\title{
Paul Ichiro Terasaki (1929-2016): Inventor of the microcytotoxicity assay and pioneer tissue typer.
}

\section{Introduction}

Paul Terasaki, one of the leading pioneers of HLA typing, especially its application to matching the donor and recipient for transplantation, died on January 25,2016 , aged 86 . Among his many contributions to the immunology of transplantation were his development, with John McCelland, of the microcytoxicity assay, which revolutionised the serology of HLA typing, his showing clearly the importance of serological crossmatching before transplantation, and his demonstration for the first time of the strong effect of HLA matching on survival of sibling to sibling kidney grafts. He eventually devoted most of his scientific career to investigating the contribution of HLA matching to transplant survival.

In 1990 Paul Terasaki edited a collection of articles for a 'History of HLA: Ten Recollections' (1). His aim was to provide personal perspectives on the early development of the field from those who were its pioneers. Since Paul, and more recently Arne Svejgaard, died the only survivors of the 13 authors of these recollections are myself, and Jon van Rood. Included in the collection is a long contribution from Paul himself. It is from this collection that you can get a real flavour of the early days of the HLA field and Paul Terasaki's own tremendously important contributions.

\section{Early life}

Paul Ichiro Terasaki was born in Los Angeles on September $10^{\text {th }}, 1929$. His parents were poor immigrants, but his father had managed to open a successful cake shop in 1941. Soon after that, however, in 1941, came Pearl Harbor and then President Roosevelt's 1942 executive order that forced Japanese, including those who were US citizens, to move to 'relocation' camps. This meant that his family lost most of their possessions and that Paul's three early high school years were spent in what was, in effect, an internment camp. After the end of World War II, when the family were released from the camp, they decided to move to Chicago, where Paul graduated from Hyde Park High School. When his family decided they had had enough of the severe Chicago winters and moved back to Los Angeles, Paul decided to study Zoology at UCLA, where eventually he got his Bachelor's, Master's and PhD degrees. After this, Paul was fortunately able 
to get a position in the Department of Surgery working on skin grafting in chickens. With the support of Professor William Longmire, the Head of the Surgery Department, he then obtained a National Cancer Institute Post Doctoral Fellowship, which enabled him to develop his interests in transplantation by spending a year (1958/9) in Peter Medawar's laboratory at University College in London. Medawar was effectively the father of transplantation research and was soon to get the Nobel Prize for his discovery of acquired immunological tolerance. It was this year in Peter Medawar's laboratory that determined Paul Terasaki's future career.

\section{Post Doctoral Fellowship with Peter Medawar}

During his time with Peter Medawar, Paul learnt how to handle blood, though mostly from chickens, learned about the importance of lymphocytes in graft rejection and was introduced to the complement dependent cytotoxicity assay. For reasons that Paul describes as "perhaps ... some sort of youthful rebellion" he went for the "humoral immunity approach to transplantation versus the cellular approach favoured by Brent and Medawar". This emphasis on the importance of antibodies for graft rejection persisted in essentially all his future work on transplantation.

While still in England, he decided he wanted to work with human sera and so obtained permission to extend his fellowship to work in Paris with Jean Dausset, who had begun to use a leukoagglutination assay for the analysis of human antisera. It seems that Dausset found it difficult to communicate with Paul because of Paul's poor French and so sent him to the Pasteur Institute, where Paul soon became discouraged and decided after a few months to return to Los Angeles (see 2).

Dausset's rebuff, which he must surely later have found to be rather embarrassing, was perhaps a blessing in disguise. Thus, when Paul started working with human material after his return to Los Angeles he correctly assessed the problems of the agglutination assays as used by Dausset, Van Rood and Rose Payne, which were not very reproducible and used mixed white blood cells. Julia Bodmer recalled Bernard Amos accusing her when she was working in Rose Payne's laboratory using the leukoagglutination assay, of using "pre civil war pipettes"! These Pasteur pipettes often had broken tips and produced droplets of serum that were quite variable in size. Paul wisely decided to work with only lymphocytes because they were more robust cells than granulocytes, and he realized that a more reproducible 
assay was needed.

\section{The microcytotoxicity assay}

Paul himself described the situation as follows: "Necessity is really the mother of invention. Both my technician, John McClelland, and I were unable to venipuncture each other, so we finger poked each other for blood" (2). It was the limitation of the available amounts of blood and serum that led Paul to the concept of a micro-test using lymphocytes. Because most of the patients they were studying were heavily immunosuppressed, the number of lymphocytes that could be obtained from them was also small. The available sera, which, following Rose Payne and Jon Van Rood's independent publications in 1958, were mainly from multiparous women due to fetal-maternal stimulation, did not readily agglutinate the lymphocytes and so Paul decided on a complement based cytotoxicity assay.

The source of complement was a key to success and he had shown that only rabbit and dog complement worked on human cells, so he chose to work with rabbit complement. Paul and Roy Walford both published papers in $1964(3,4)$ on the use of rabbit complement in anti-lymphocyte cytotoxicity assays, but Walford was often given the credit for this, perhaps because his paper was published a little earlier and in Science rather than the more obscure Annals of the New York Academy of Sciences. In the Terasaki et al 1964 (3) paper, they say that Walford's work was "coincident" with theirs. However, in the 1990 history he says "After we mentioned the importance of Rabbit C' to Roy Walford... he tested many animal sources and agreed that Rabbits were the best." This was clearly a sensitive priority issue with Paul, expressed in his usual gentle but firm manner.

Terasaki and McCelland's 1964 (5) development of the microcytotoxicity assay was the real revolution in technique that drove the initial serological identification of well-defined specificities. The proteins carrying these specificities were later shown to be the products of the genes that collectively came to be called the HLA system.

As originally described, the microcytotoxicity assay was very fiddly. The neutrophils were removed from small amounts of buffy coat by sticking them to glass, grease pencils were used to delineate areas for the assays under drops of oil, double size cover slips were stuck to wooden frames with 
scotch tape, dead cells were identified using an inverted microscope and a bit of interpretative skill, and then there was the need for careful choice of rabbit complement, absorbed out with red cells to avoid non-specific killing. Fortunately, Hamilton, who made the syringes that delivered microlitre amounts of fluid, was a local Los Angeles company. Although the assay worked well in the skilled hands of Paul and his colleagues, it was not quickly taken up by others, probably because it was so fiddly and somewhat cumbersome to do, compared with just adding a few drops of serum, however variable in size, to mixed white blood cells and looking for clumping.

Paul, however, was full of practical ideas for making things happen that would ease the burden of serological testing of lymphocytes with a view to improving the outcome of transplantation. He devised clever ways to ship blood by regular airmail from Paris to Los Angeles to enable their collaborations with Dausset's laboratory. Terasaki and McCelland also described the first freezing of lymphocytes for typing. The large coverslip attached by scotch tape to a frame morphed in 1968 into the plastic disposable Terasaki microtest plate, which is with us to this day. This plate was the precursor of all the plate assays used nowadays for the small scale testing of cells in a wide variety of assays. It seemed at one point that it would be overtaken by 96 well plates, but now we have 384, 768 and 1536 well plates! Paul persuaded Falcon to produce the plates but UCLA refused to patent them because they thought they would not sell enough! Soon came multiple dispensers and better lymphocyte separation.

Julia Bodmer and I published one paper together with Paul and his colleagues in 1966 (6), almost exactly 50 years ago. This was before we had developed our own typing laboratory but well after we had described the $H L A-A$ (LA) locus with Rose Payne in 1964 (7). By that time we already had good software for analysing serum reactions for the definition of HLA antigens. The aim of the 1966 paper was to show that Paul's microcytotoxicity assay could pick up the same antigens as had been defined by the much cruder and less reliable agglutination assay used in Rose Payne's laboratory. We thus did the first computer analysis of Paul's data with a view to defining the antigens. These data were obtained with the microcytotoxicity assay on 200 volunteers in Los Angeles using Rose Payne's sera defined by agglutination. Considering the data as a whole, we were able to show that there was good agreement between the cytotoxicity and agglutination assays. Ray Mickey, who was an absolute mainstay of 
Paul's data analysis for 25 years until he retired in 1989, very soon took over the analysis of Paul's serological data for antigen definition.

Paul's assay was a godsend to Julia and me when I got my first separate laboratory in 1966. We, however, added fluorescence - fluorochromasia - to the test, making the assessment of dead cells much easier (8). This and other developments that simplified the recognition of both dead and living cells and the isolation of lymphocytes, turned the microcytotoxicity assay into a simple and very reliable test that became the main basis for HLA typing until the development of DNA based assays.

\section{HLA matching and transplant survival}

Paul's initial interest in applying his serological assays was not so much in the definition of the antigens but in the investigation of the correlation between matching, using a collection of largely uncharacterised serum reactions, and graft survival. He was also concerned with testing for the presence of lymphocytotoxic antibodies in transplant patients on the assumption that lymphocytes carried the same antigens as those present on kidneys that led to graft rejection. In his contribution to the first of the major Histocompatibility Testing Workshops in Duke in 1964, he provided the first example in human kidney transplantation of acute rejection due to the presence of antibodies in the recipient that reacted with the lymphocytes of the donor and introduced the concept of "crossmatching". These data were substantially enlarged on in a later, widely quoted publication (9). These results proved the idea that in humans the lymphocytes carried the antigens that led to graft rejection, as Medawar had originally proposed from his work with rabbits.

Perhaps the best early evidence for the role of HLA matching in transplantation was obtained by Singal, Mickey, and Terasaki in 1969 (10). They showed a huge difference between matched and non-matched siblings in the survival of kidney transplants (Fig 1). Even though at that time the matching was only for a relatively few types, that was enough to identify the HLA identical siblings. I still show their figure on this as the best direct evidence for the effect of HLA matching on graft survival and its role as the human major histocompatibility system.

Paul comments in his 1990 perspective (1) that, in studying the effects of HLA matching on transplantation, he decided to go directly to the study of 
kidney transplants, as he did not believe that surgeons would be convinced by a few extra days of skin graft survival. The streamlining and early automation of the microcytotoxicity assay enabled the very large numbers of tests that were needed for studying the effects of matching. Ironically, given the results Paul and his colleagues had obtained by comparing matched and un-matched sibling transplants, the first data that he presented on matching for non-sibling kidney grafts at the 1970 congress of the Transplantation Society showed that HLA matching using the then available knowledge of the system did not show any correlation between matching and kidney graft survival. These results were not well received and were not published in the proceedings of the meeting, but only later in Tissue Antigens (11), and actually led to Paul losing his NIH grant support. In retrospect, it is hardly surprising that Paul obtained these negative results given the very limited knowledge of the HLA system at that time and the fact that the effects of matching were necessarily being judged against a background of strong immunosuppression.

The traumatic loss of his NIH support turned out strangely, once again to be a blessing in disguise. This was because, as he later said (2), “...it pressed me to survive on my own by selling tissue-typing trays to provide research funds." This enabled him to continue his research and stimulated him to develop a registry to explore why a correlation between HLA matching and kidney graft survival had not been found. Maintaining this registry and its successors became a major part of his subsequent research activity and led to many publications eventually documenting that, with adequate HLA typing, there were significant beneficial effects of matching for unrelated donors even in the presence of strong immunosuppression.

One of Paul's key contributions to the eventual successful application of HLA matching to kidney transplantation was the development, with Geoffrey Collins in 1969, of a process for preserving kidneys long enough to enable them to be shipped using commercial carriers (14). They tested their system by shipping dog kidneys from Los Angeles to London, Tel Aviv and Sydney using commercial airlines. Collins then followed the shipped kidneys round the world to implant them successfully into local dogs in London, Tel Aviv and Sydney. The Collins et al process still remains the basis for successful short-term preservation of kidneys for transplantation, which is essential if HLA matching is to be taken into account.

\section{HLA and disease associations: B27 and ankylosing spondylitis}


Paul, like many of us in the HLA field towards the end of the 1960s and in the early 1970s, became very involved in the search for correlations between HLA types and diseases. His most striking result was to show the extraordinarily strong association between B27 and ankylosing spondylitis, still one of the strongest of all the associations (12). This was 'coincident' with the work of Brewerton and colleagues in 1973 (13). However, as Paul relates (2), having asked the rheumatologists what would be the most interesting disease to study, they looked at gout, which had a reputation for a strong heritable component, and they took the patients in the adjacent ward to those with gout as their controls. To their amazement, it was the controls that showed the HLA B27 association, and this was because they were all males with ankylosing spondylitis! This early discovery led Paul, I believe, to the assumption that only such very strong associations would have any useful applications and so to disillusionment with the weaker associations, including those found with rheumatoid arthritis or juvenile onset diabetes. He did not, I think, appreciate the contributions that these other discoveries would later make to understanding the immune aetiology of so many of these diseases.

\section{International Histocompatibility Testing Workshops: $1970\left(4^{\text {th }}\right)$ and $1980\left(8^{\text {th }}\right)$}

The international workshops, starting with the first at Duke University in 1964 and continuing to the $16^{\text {th }}$ in Liverpool in 2012, with a $17^{\text {th }}$ planned for 2017 in California, have played an absolutely major role in the development and definition of the HLA system. It is only through the extensive exchange of reagents and cells, and agreements on nomenclature, that it became possible to unravel the complexity of HLA, starting from the antigens defined by crude serology and relatively simple statistical analysis. Paul was a full participant in the workshops from the beginning and a strong believer in the importance of international exchanges of materials. As he rightly said in his 1990 perspective (2), "Either you participated in the International Workshops, or you were not in the field."

He is the only one of the tissue-typing pioneers to have organised two workshops, both in Los Angeles. The first, in 1970, started a widespread international exchange of antisera and promoted the microcytotoxicity test as the standard to be used. This led to an improved definition of many HLA determinants. The second, in 1980, focused on applications of HLA typing 
to transplant matching and disease associations, especially with the then relatively recently defined HLA-DR specificities. Organising these two workshops demonstrated his strong commitment to international collaboration, which was extended by his long running international cell exchange and his openness in distributing the resulting information. These practices were pioneered by the HLA community long before they became commonplace in the development of the human genome project.

\section{Commercial developments and Philanthropic contributions}

Paul's initiative in selling tissue-typing trays to provide research funds was eventually the basis for his founding the transplant diagnostics company, One Lambda, Inc., in 1984. Its aim, as defined on its web site, was "to develop and provide transplant centers worldwide with the tools needed to better match their patients and monitor them pre/post-transplant". The company was very successful and was sold in 2012 for just under \$1billion to Thermo Fisher Scientific.

The success of One Lambda enabled Paul to become a significant benefactor to a variety of causes, especially UCLA, his much-loved alma mater, and to Japanese American activities. He did this with his wife, Hisako, who is a distinguished artist, whom he married in 1954 after their meeting in the local Methodist church.

In 2001, Paul established an endowed chair at UCLA in US-Japan relations, and in 2006, Paul and Hisako contributed $\$ 5$ million to UCLA to create the Paul I. and Hisako Terasaki Center for Japanese studies. In 2010, UCLA announced a gift from Paul of $\$ 50$ million to create the Terasaki Life Sciences Building and endow the Paul I. Terasaki Chair in Surgery as well as two postdoctoral fellowships in transplantation.

Paul, although he would recount openly his difficult time in the internment camp, never showed any bitterness towards the USA. Notably, he and Hisako supported causes committed to the preservation of the history of Japanese Americans and to Japanese/American physician interactions. For his support of UCLA, Paul was awarded the 2011 UCLA Edward A. Dickson Alumnus of the Year award, and in June 2012 the UCLA medal, its highest honour,. 


\section{Epilogue}

Paul published more than 800 papers and served on several editorial boards. In 1988, he received the Rose Payne Distinguished Scientist Award of the American Society for Histocompatibility and Immunogenetics (ASHI), and in 1996, he shared the Medawar prize of the Transplantation Society with Jean Dausset and Jon van Rood. In 2003, ASHI established the Paul I. Terasaki Clinical Science Award "to honor an individual, group, or institution in recognition of significant accomplishments and/or contributions to the fields of clinical transplantation, histocompatibility, and immunogenetics".

I had the privilege of taking part in a Memorial for Paul Terasaki arranged by his colleagues and family at UCLA on $6^{\text {th }}$ March 2016 . The tributes to Paul from scientists, politicians, family and friends, and the response of the audience made it a most moving event that showed how much he will be missed by so many people, most especially by his family and close colleagues.

Paul Ichiro Terasaki's life and contributions to science are a remarkable and genuine example of going from 'rags to riches' both literally and figuratively through his scientific contributions, which have benefited so many transplant patients.

\section{References}

1.Terasaki PI, ed. History of HLA. Ten Recollections. Los Angeles: UCLA Tissue Typing Laboratory; 1990.

2. Cecka, M J(2003) Interview with Dr Paul Terasaki American Journal of Transplantation 3 (9): 1047-1051.

3. Terasaki, PI, Mandell M, Van de Water J, Edgington, T S (1964) Human blood lymphoctye cytotoxicity reactions with allogenic antisera. Annals of the New York Academy of Sciences. 120, 322- 334

4. Walford, R L, Gallagher R, Sjaarda J R. (1964) Serologic Typing of Human Lymphocytes with Immune Serum Obtained after Homografting. Science 144, 868 - 870

5. Terasaki PI, McClelland JD. Microdroplet assay of human serum cytotoxins. Nature 1964; 204: 998-1000 
6. Bodmer, J., Bodmer, W.F., Payne, R., Terasaki, P. and Vredovoe, D. (1966). Leukocyte antigens in man: a comparison of lymphocytotoxic and agglutination assays for their detection. Nature 210, 28-31.

7. Payne, R., Tripp, M., Weigle, J., Bodmer, W.F., and Bodmer, J. (1964). A new leukocyte isoantigen system in man. Cold Spring Harbor Symposia on Quantitative Biology 29, 285-295.

8. Bodmer, W.F., Tripp, M., and Bodmer, J. (1967). Application of a fluorochromatic cytotoxicity assay to human leukocyte typing. In Histocompatibility Testing 1967. Report of a Conference and Workshop Torino and Saint-Vincent, Italy, 14-24 June 1967, E.S. Curtoni, ed. (Copenhagen: Munksgaard), pp. 341-350.

9. Patel R, Terasaki PI. Significance of the positive crossmatch test in kidney transplantation. N Engl J Med 1969; 280: 735-739.

10. Singal, D P; Mickey, M R; Terasaki, P I (1969) Serotyping for homotransplantation: XXIII. Analysis of Kidney Transplants from Parental versus Sibling Donors. Transplantation 7 (4) 246-255

11. Mickey MR, Kreisler M, Albert ED, Tanaka N, Terasaki PI. Analysis of HLA incompatibility in human renal transplants. Tissue Antigens 1971; 2: 57-67.

12. Scholsstein L, Terasaki PI, Bluestone R, Pearson CM. High association of an HLA antigen, w27, with ankylosing spondylitis. N Engl J Med 1973; 228: 704-706

13. Brewerton A, Hart F D, Nicholls A, Caffrey M, James D C O, Sturrock R D, (1973) Ankylosing spondylitis and HL-A 27. Lancet April $28^{\text {th }} 904-$ 907.

14. Collins GM, Bravo-Shugarman M, Terasaki PI. Kidney preservation for transportation. Initial perfusion and 30 hour ice storage. Lancet 1969; ii: 1219. 
Figures

Photo of Paul Ichiro Terasaki

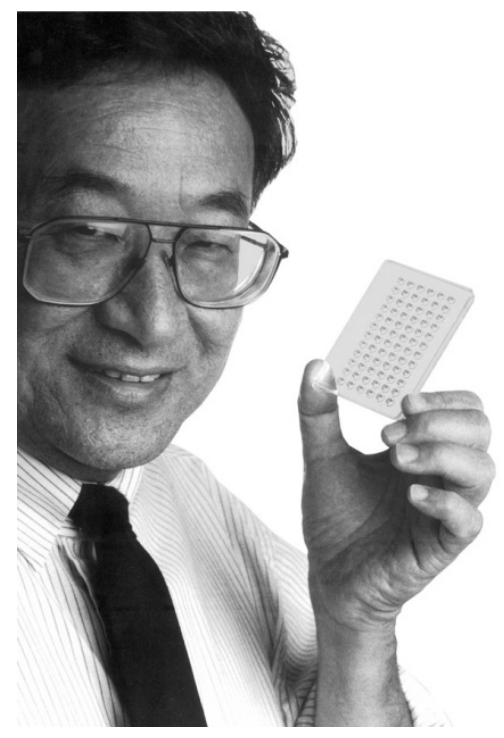


Figure 1

Survival curves for matched and mismatched sibling transplants (from ref 10).

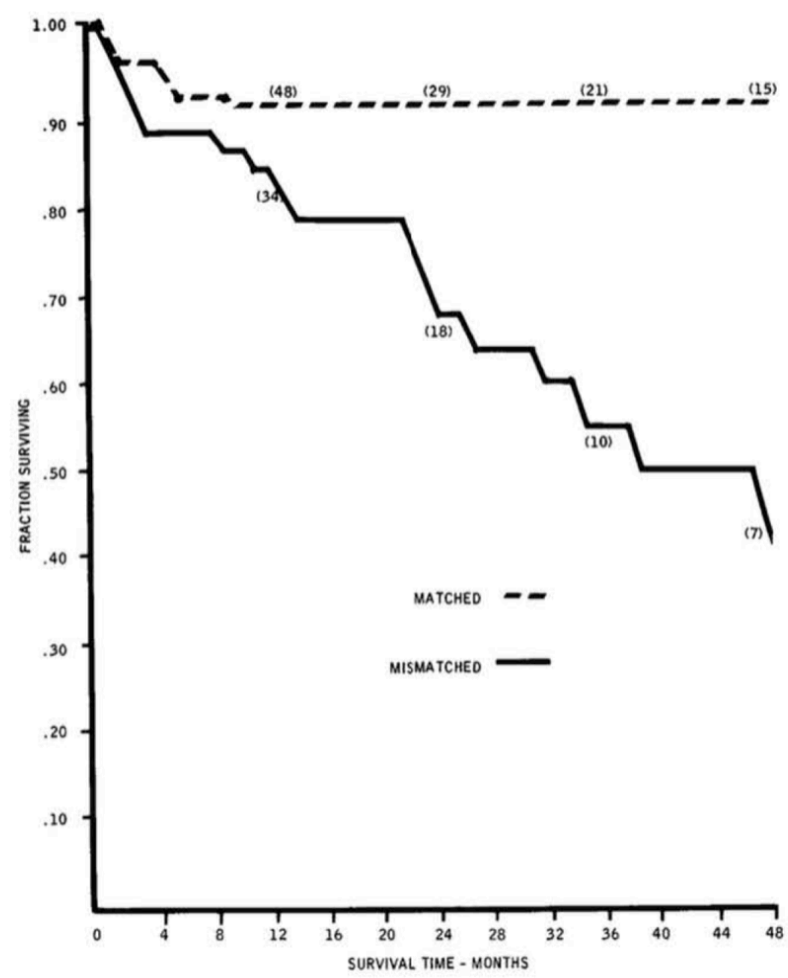

